Check for updates

Cite this: Chem. Sci., 2019, 10, 8812 have been paid for by the Royal Society of Chemistry
๑ All publication charges for this article

\section{Controlled chemoselective defluorination and non-defluorination for [5 + 1] aromatic annulation via Meisenheimer-type nitrogen anion and radical intermediates $\uparrow$}

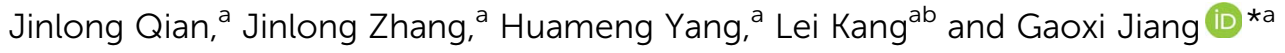

Received 1st July 2019

Accepted 5th August 2019

Reported is a unique chemoselectivity approach to base-promoted defluorinative and $\mathrm{Cu}(\mathrm{I})$-catalyzed aerobic oxidative non-defluorinative [5 +1$]$ condensation aromatizations of simple unsaturated ketones with ammonium salts via Meisenheimer-type nitrogen anion and radical intermediates. The $\mathrm{CuBr} / \mathrm{O}_{2}$ catalysis provides a straightforward approach to diverse 3-fluoropyridines in high yields. The synthetic utility of the strategy is highlighted by the concise synthesis of several F-modified bioactive compounds.

DOI: $10.1039 / \mathrm{c} 9 \mathrm{sc0} 03216 \mathrm{a}$

rsc.li/chemical-science
Organofluorine chemistry has played a privileged role in all aspects of pure and applied chemistry. ${ }^{1}$ It is well known that introduction of a fluorine atom into a molecule could significantly modify its biological properties. ${ }^{2}$ Exploitation of highly chemoselective synthetic strategies to obtain easily accessible organofluorine compounds of biological importance is an attractive method. Theoretically, effective control of intermediate conversion is one of the origins of chemoselective synthesis. Nucleophilic aromatic substitution $\left(\mathrm{S}_{\mathrm{N}} \mathrm{Ar}\right)$ of fluorinated arenes is a versatile synthetic tactic. Nevertheless, the exhaustive defluorination is rather inevitable via Meisenheimer intermediates (Scheme 1, eqn (1)). ${ }^{3}$ 3-Fluoro-2 $H$-pyridin-1-ide should be more reactive due to the electronegativity of the nitrogen atom and fluorine substitution. Such a Meisenheimertype nitrogen complex might follow two reaction pathways: defluorination (Scheme 1, eqn (2i)) and non-defluorination (eqn (2ii)), the latter has not been realized so far. Herein, we report a unique chemoselectivity approach to base-promoted defluorinative and $\mathrm{Cu}$-catalyzed aerobic oxidative non-defluorinative [5 +1 ] condensation aromatizations of simple unsaturated ketones with ammonium salts (eqn (3)). The strategy features a formal $\mathrm{C}_{\mathrm{sp}^{2}}-\mathrm{H}$ activation, good atom-/step-economy, and wide substrate scope, providing a new practical approach to diverse pyridines. The usefulness of this method is highlighted in the concise total synthesis of a blood lipid regulator, its fluorinemodified analogues and fluorine-modified AMPK receptor inhibitor. Preliminary mechanism investigation reveals that the

${ }^{a}$ State Key Laboratory for Oxo Synthesis and Selective Oxidation, Center for Excellence in Molecular Synthesis, Suzhou Research Institute of LICP, Lanzhou Institute of Chemical Physics (LICP), Chinese Academy of Sciences, Lanzhou 730000, P. R. China.E-mail: gxjiang@licp.cas.cn

${ }^{b}$ University of Chinese Academy of Sciences, Beijing 100049, P. R. China

$\dagger$ Electronic supplementary information (ESI) available. See DOI: 10.1039/c9sc03216a
$[\mathrm{Cu}] / \mathrm{O}_{2}$ oxidative catalysis involves a single electron transfer (SET) process and unprecedentedly interrupts the traditional preponderant defluorination of Meisenheimer-type intermediates.

The pyridine skeleton is a fundamental moiety in bio-, chemical-, and pharmaceutical molecules. ${ }^{4}$ Among these, 3fluoropyridine as a core fragment is widespread in the design of pharmaceuticals. ${ }^{5}$ Currently available methods toward 3-fluoropyridines involve the Balz-Schiemann reaction, electrophilic/ nucleophilic fluorination, deoxofluorination, and Rh-catalyzed $[4+2]$ cyclization, which always suffer from narrow scope,

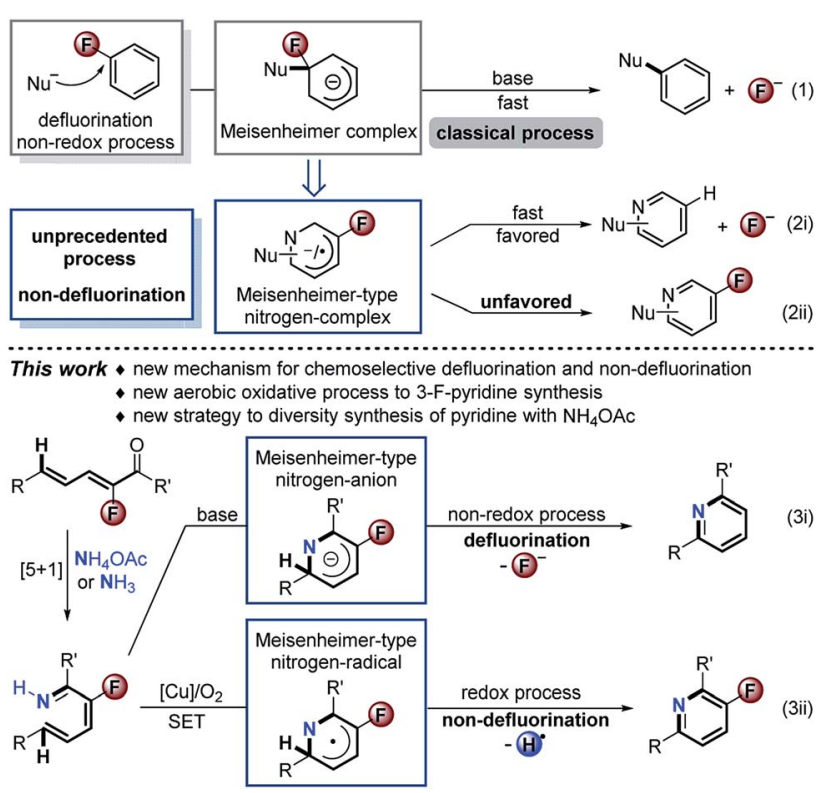

Scheme 1 Traditional $\mathrm{S}_{\mathrm{N}} \mathrm{Ar}$ defluorination and current chemoselective defluorination/non-defluorination via [5+1] aromatic annulation. 
poor chemoselectivity, and requirement of expensive raw materials. ${ }^{5}$ In this regard, development of a new practical access is still in great demand. In principle, the straightforward [5+1] cyclization of 2-fluoro-2,4-dien-1-ones with simple ammonium salts or free ammonia represents the state-of-the-art tactic from the standpoint of atom and step economy, ${ }^{6}$ but still is undisclosed reasonably because of the overwhelmingly competitive defluorination. By an oxidative SET/radical strategy, we anticipate that efficiently non-defluorinative aromatization of the aforementioned Meisenheimer-type nitrogen intermediate could be a potential solution to the issue.

Initially, in order to verify the feasibility of the designed [5+ 1] aromatic annulation, we treated a wide range of 2-fluoro-2,4dien-1-ones 1 with a simple ammonium salt, $\mathrm{NH}_{4} \mathrm{OAc}(5.0$ equiv.) under basic conditions $\left(\mathrm{Cs}_{2} \mathrm{CO}_{3}\right)$ in DMSO at $120^{\circ} \mathrm{C}$ for $12 \mathrm{~h}$. As shown in Scheme 2, the reactions (Scheme 1, eqn (3i)) took place smoothly and gave a series of pyridines $2 \mathbf{a}-\mathbf{r}$ in excellent yields via complete defluorination regardless of the steric hindrance and electronic properties of substituents (for optimization of the reaction conditions, see the ESI $\dagger$ ).

Encouraged by the above results and the recent surge of interest to develop copper-catalyzed aerobic oxidation reactions of amines, ${ }^{7}$ we anticipate that $\mathrm{Cu} / \mathrm{O}_{2}$-catalysis might have the potential to interdict fluoride displacement of Meisenheimertype intermediates to realize the first access to 3-fluoropyridines through a straightforward [5+1] cyclization with simple ammonium salts and free ammonia as the sole nitrogen source. As shown in Table 1, the reaction of 2-fluoro-1,5-diphenylpenta2,4-dien-1-one 1a with $\mathrm{NH}_{4} \mathrm{OAc}$ (5.0 equiv.) in the presence of $\mathrm{CuBr}(10 \mathrm{~mol} \%)$ in a mixed solvent (DMSO/toluene, $5 \% \mathrm{v} / \mathrm{v}$ ) at $140{ }^{\circ} \mathrm{C}$ in a sealed $\mathrm{O}_{2}$ atmosphere for $12 \mathrm{~h}$ afforded $3 \mathrm{a}$ in $17 \%$ yield. Surprisingly, as a sharp contrast to the defluorinative aromatic annulation (Scheme 2), only a trace of the

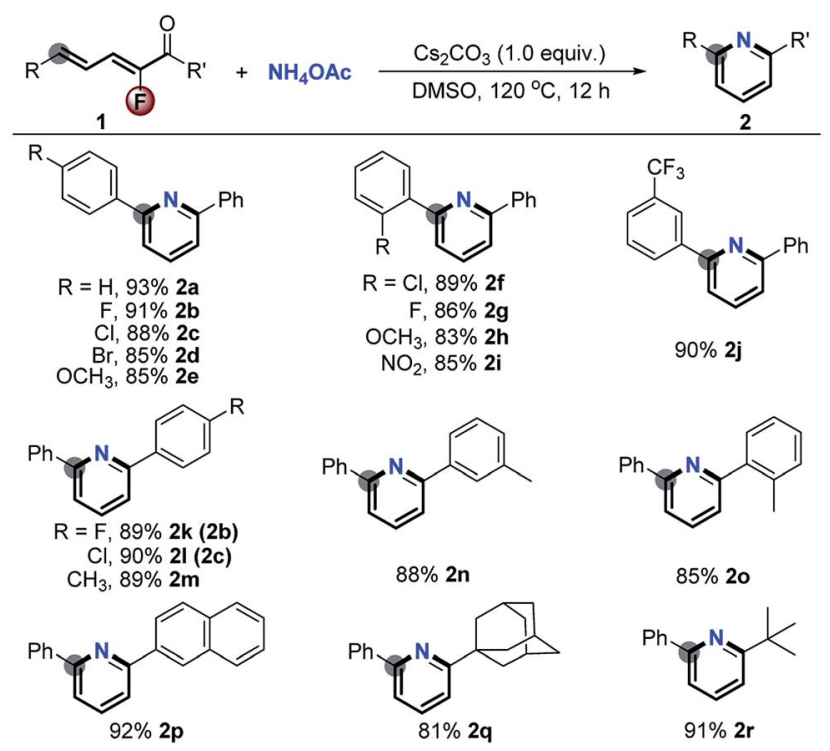

Scheme 2 Results to verify the feasibility of [5+1] aromatic annulation under basic conditions via defluorination. ${ }^{a}{ }^{a} 1(0.1 \mathrm{mmol}), \mathrm{NH}_{4} \mathrm{OAc}(5.0$ equiv.), $\mathrm{Cs}_{2} \mathrm{CO}_{3}$ (1.0 equiv.), $12 \mathrm{~h}$, at $120^{\circ} \mathrm{C}$, DMSO (1.0 mL). Yields of isolated products are given.
Table 1 Optimization of the reaction conditions ${ }^{a}$

$\begin{array}{lll} & & \\ & & \\ & & \\ & & \end{array}$

${ }^{a}$ 1a (0.1 mmol), $\mathrm{NH}_{4} \mathrm{OAc}$ (5.0 equiv.), $\mathrm{O}_{2}\left(1 \mathrm{~atm}\right.$, closed), $12 \mathrm{~h}$, at $140{ }^{\circ} \mathrm{C}$, $5 \%(\mathrm{v} / \mathrm{v}) \mathrm{DMSO} /$ toluene $(1.0 \mathrm{~mL})$, yields given by GC-MS using $n^{-}$ dodecane as an internal standard. ${ }^{b}$ Yield of isolated 3 a was given in the parentheses. ${ }^{c}$ Using $\mathrm{NH}_{4} \mathrm{Cl}$ instead of $\mathrm{NH}_{4}$ OAc. ${ }^{d}$ Using $\mathrm{NH}_{3}$ (in $\mathrm{MeOH}$ ) instead of $\mathrm{NH}_{4} \mathrm{OAc}$.

defluorinated product 2a was detected in the Cu-catalyzed aerobic oxidation process (entry 1). Stimulated by the excellent ratio of the non-defluorinative and defluorinative product (chemoselectivity) and promising yield, further optimization of the reaction conditions was carried out to improve the yield. To our delight, just addition of $10 \mathrm{~mol} \%$ trifluoroacetic acid (TFA) dramatically increased the yield from $17 \%$ up to $89 \%$ with only $2 \%$ loss of fluorine in the product (entry 2), reasonably due to the facilitative formation of imine which is the real intermediate in this $\mathrm{Cu}$-catalyzed aerobic oxidation reaction. Lowering the loading of $\mathrm{CuBr}$ to $5.0 \mathrm{~mol} \%$ decreased the yield to $59 \%$ (entry 3). Other catalysts including $\mathrm{CuCl}, \mathrm{CuI}, \mathrm{Cu}(\mathrm{MeCN})_{4} \mathrm{PF}_{6}$, $\mathrm{CuBr}_{2}, \mathrm{FeBr}_{2}$ and $\mathrm{MnBr}_{2}$ had adverse effects on the reaction (entries 4-9). Other acids such as HOTf and HOAc had a detrimental effect on the yield but still without release of fluorine (entries 10 and 11). $\mathrm{NH}_{4} \mathrm{Cl}$ and free $\mathrm{NH}_{3}$ (in $\mathrm{MeOH}$ ) as nitrogen donors also showed acceptable performance (entries 12 and 13). The competitive dehalogenative aromatization was dominant if the reaction took place in air (entry 14). As expected, only dehalogenative aromatization occurred in the absence of $\mathrm{O}_{2}$ or $\mathrm{CuBr}$ catalyst (entries 15 and 16).

As illustrated in Scheme 3, the CuBr/TFA oxidative catalysis effectively converted a series of 2-fluoro-2,4-dien-1-ones with $\mathrm{NH}_{4} \mathrm{OAc}$ into diverse polysubstituted 3-fluoropyridine derivatives in good yields with excellent chemoselectivity. Different groups including halide, methoxyl and nitro in the 5-aromatic ring were well tolerated, giving the corresponding products $\mathbf{3 a - j}$ in good yields (71-82\%) and excellent chemoselectivity of more 

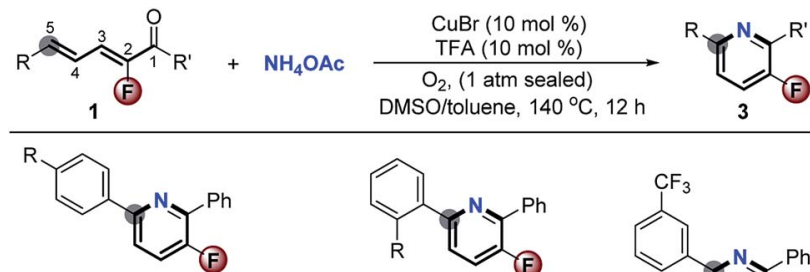

$\mathrm{R}=\mathrm{H}, 3 \mathrm{a}, 80 \%,{ }^{b}(98: 2)$

F, 3b, 75\%, (95:5)

Cl, 3c $72 \%,(98: 2)$

$\mathrm{Br}, 3 \mathrm{~d}, 74 \%$, (95:5)

$\mathrm{OCH}_{3}, 3 \mathbf{e}, 81 \%,(97: 3)$

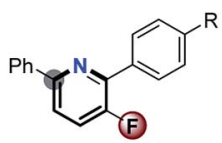

$\mathrm{R}=\mathrm{F}, \mathbf{3 k}, 67 \%,(95: 5)$ Cl, 3I, $75 \%,(95: 5)$ $\mathrm{CH}_{3}, 3 \mathbf{m}, 72 \%$, (96:4)

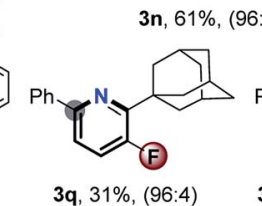

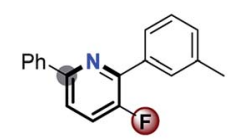

n, $61 \%,(96: 4)$

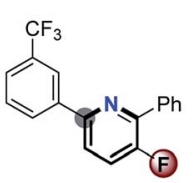

3j, $78 \%,(95: 5)$
$=\mathrm{Cl}, 3 \mathbf{3}, 82 \%,(98: 2)$ F, 3g, 75\%, (95:5) $\mathrm{OCH}_{3}, 3 \mathbf{h}, 75 \%$, (96:4) $\mathrm{NO}_{2}, 3 \mathbf{i}, 71 \%$, (95:5)

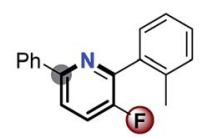

3o, $59 \%$, (95:5)<smiles>[2H]c1ccc(-c2ccccc2)nc1-c1ccc2ccccc2c1</smiles>

3p, $85 \%$, (97:3)

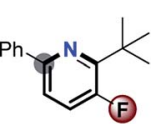

$3 r, 65 \%,(95: 5)$

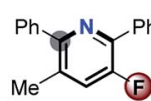

3s, $65 \%$, (90:10)
Scheme 3 Scope of 2-fluoro-2,4-dien-1-ones for CuBr-catalyzed aerobic oxidative non-dehydrofluorinative $[5+1]$ condensation aromatizations. ${ }^{a} 1 \mathrm{a}-\mathrm{s}(0.1 \mathrm{mmol}), \mathrm{NH}_{4} \mathrm{OAc}\left(5.0\right.$ equiv.), $\mathrm{O}_{2}$ ( $1 \mathrm{~atm}$, closed), $12 \mathrm{~h}$, at $140{ }^{\circ} \mathrm{C}, 5 \%(\mathrm{v} / \mathrm{v})$ DMSO/toluene $(1.0 \mathrm{~mL}) .{ }^{b}$ Yield of isolated products are given. ${ }^{\circ}$ The ratio of non-defluorinative and defluorinative products in the parentheses was determined by GC-MS using $n$-dodecane as an internal standard.

than $95: 5$. Substrates with $\mathrm{F}, \mathrm{Cl}$ and methyl at the carbonyl aromatic ring were also applicable, delivering the products $3 \mathbf{k}-\mathbf{o}$ in $59-75 \%$ yields without negative effects on fluorine retention. Reasonably, steric hindrance had a strong effect on the reactivity. Surprisingly, the more bulky substrate 1p, especially adamantyl (1q) and tert-butyl 2-fluoro-2,4-dien-1-one (1r) were also compatible with the direct $[5+1]$ aromatic annulation without any defluorination although the yields of the desired adducts $3 \mathbf{p}-\mathbf{r}$ were decreased from $85 \%$ to $31 \%$ on account of the increase of steric hindrance. The 4-methyl substituted starting material $1 \mathrm{~s}$ was readily converted into the multifunctional 3-fluoropyridine 3s with moderate result.

Stimulated by the satisfactory performance and to further evaluate the generality of the valuable approach, we next extended the scope of substrates to diverse types of $\alpha$-fluoro- $\alpha, \beta$ unsaturated inert aromatic ketones. As demonstrated in Scheme 4, several hetero-polycyclic fused 3-fluoropyridines 5a-d were easily obtained in good yields with $>97: 3$ chemoselectivity via a formal $\mathrm{C}_{\mathrm{sp}^{2}}-\mathrm{H}$ activation. This reaction provides a practical access to such useful kinds of compounds which are generally difficult to synthesize by traditional methods. ${ }^{5}$ Significantly, with (Z)-3-(benzofuran-3-yl)-2-fluoro-1-phenylprop-2-en-1-one $\mathbf{4 e}$ and (Z)-3-(benzo[b]thiophen-3-yl)-2-fluoro-1-phenylprop-2-en-1-one $\mathbf{4 f}$ as the reactants, the concomitant cleavage of $\mathrm{C}-\mathrm{O}$ and $\mathrm{C}-\mathrm{S}$ bonds happened during the aromatic cyclization to exclusively furnish the corresponding 2-(5-fluoro-6-phenylpyridin-3-yl)phenol 5e and 2-(5-fluoro-6-phenylpyridin-3-yl)benzenethiol 5f in 68\% and 63\% yields, respectively.
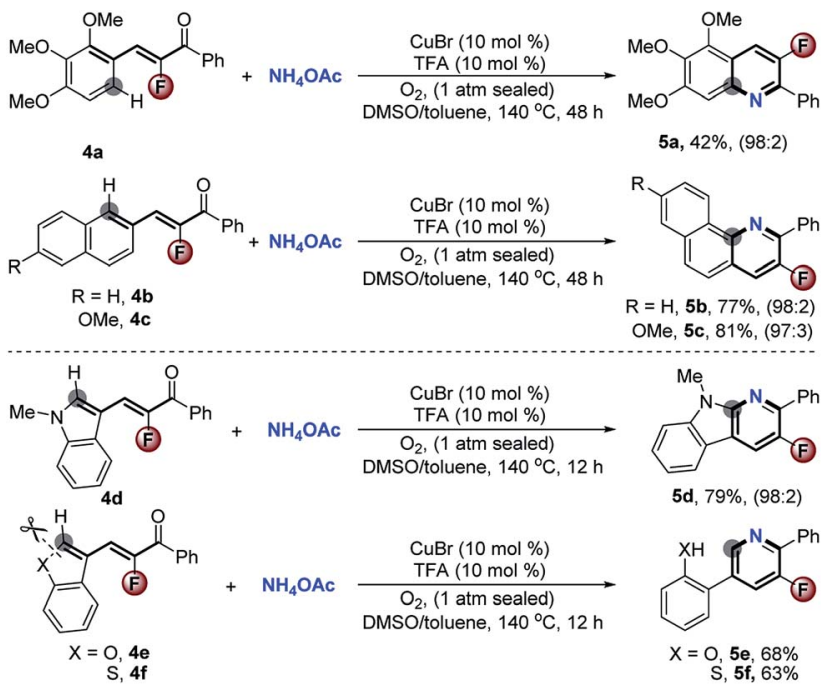

Scheme 4 Scope of typical $\alpha$-fluoro- $\alpha, \beta$-unsaturated ketones for the $\mathrm{CuBr}$-catalyzed aerobic oxidative reaction.

Finally, the synthetic utility of this $[5+1]$ aromatic annulation was highlighted by the concise synthesis of several bioactive compounds (Scheme 5). Accordingly, treatment of 1t under basic (Scheme 2) and Cu-catalyzed aerobic oxidation conditions (Scheme 3) could exclusively afford 2t and its F-substituted derivative 3t in $90 \%$ and $78 \%$ yields, respectively. Demethylation of $2 \mathbf{t} / 3 \mathbf{t}$ by $\mathrm{BBr}_{3}$ gave $\mathbf{6 a} / \mathbf{b}$ in good yields. After etherification with $\mathrm{ClCCH}_{2} \mathrm{CO}_{2}$ Et and hydrolysis, acids $\mathbf{8 a} / \mathbf{b}$ could be isolated in good yields. Blood lipid regulator $\mathbf{9 \mathbf { a } ^ { \mathbf { 8 } }}$ and its F-modified

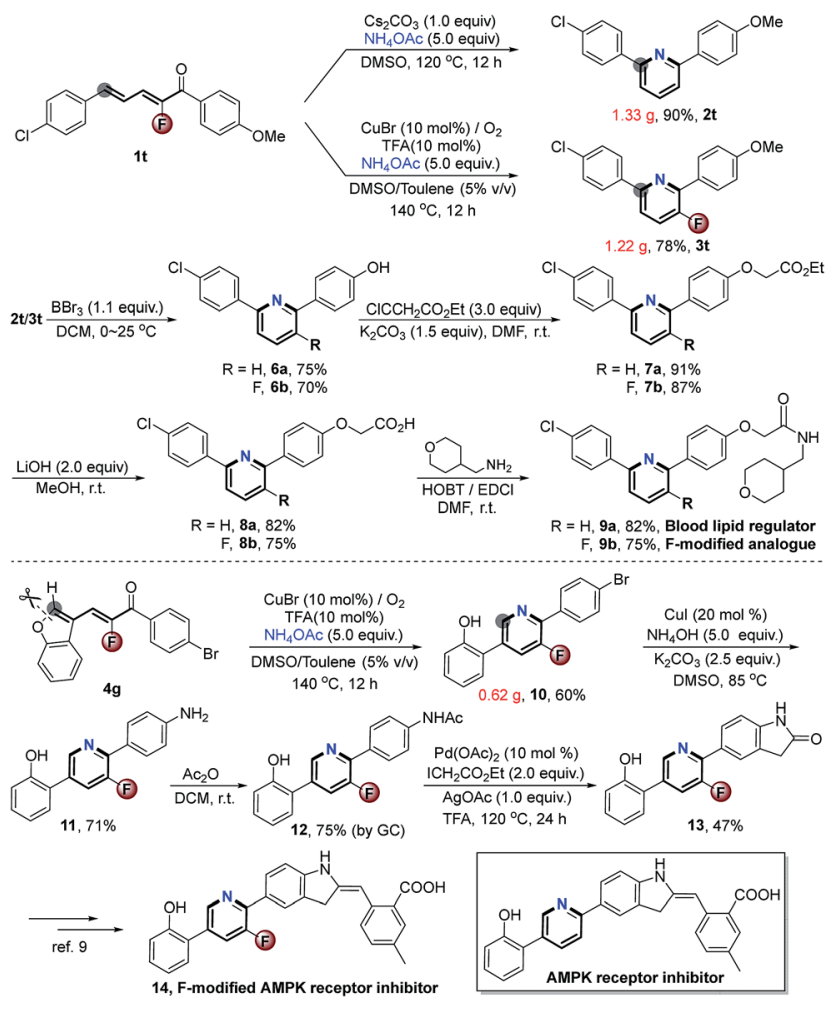

Scheme 5 Concise synthesis of F-modified bioactive compounds. 
analogue 9b were easily obtained via direct amidation with (tetrahydro-2H-pyran-4-yl)methanamine. Valuably, this method avoided the use of noble transition-metal catalysts which are indispensable in conventional approaches. Another interesting utilization is to prepare the key intermediate 13 of the Fmodified AMPK receptor inhibitor $14 .^{9}$ Via $[5+1]$ aromatic cyclization and concomitant ring-opening of furan, the $\mathrm{Cu}$ catalyzed aerobic oxidation could facilitate the synthesis of 2(6-(4-bromophenyl)-5-fluoropyridin-3-yl)phenol 10 with high step-economy by employing $\mathbf{4} \mathbf{g}$ as the starting substrate. Upon CuI-catalyzed amination with $\mathrm{NH}_{4} \mathrm{OH}$ followed by acetylation, 10 was smoothly converted into $\mathbf{1 2}$ in acceptable GC-yield. Compound 13 was formed in $47 \%$ yield by reacting 12 with $\mathrm{ICH}_{2} \mathrm{CO}_{2} \mathrm{Et}$ in the presence of a Pd catalyst. The 4-step reaction provided 13 in total $15 \%$ yield. Otherwise, the traditional process for the preparation of its defluorinated complex requires 8 steps in about 10\% yield. Obviously, the current approach offers great advantages in terms of efficiency and low cost.

To gain insight into the mechanism, a series of deuterium labeled control reactions were executed (Scheme 6). Under the basic reaction conditions (Scheme 2), the treatment of $\mathrm{NH}_{4} \mathrm{OAc}$ D7 instead of $\mathrm{NH}_{4} \mathrm{OAc}$ with 1a gave $2 \mathbf{a}$ and $\mathbf{2 a - D}$ in $91 \%$ yield with a ratio of $4: 1$ (eqn (1)). No deuterium labeled product was detected when $1 \mathbf{a}-\boldsymbol{D}$ reacted with $\mathrm{NH}_{4} \mathrm{OAc}$ under the same reaction conditions (eqn (2)). Using $\mathrm{D}_{2} \mathrm{O} / \mathrm{DMSO}(5 \%, \mathrm{v} / \mathrm{v})$ as the solvent, the yield of $2 \mathbf{a}$ and $2 \mathbf{a}-\mathbf{D}$ was $87 \%$ with a ratio of $7: 3$ (eqn (3)), which reveals the hydrogen exchange between the substrates and $\mathrm{H}_{2} \mathrm{O}$ during the reaction process. In dramatic contrast, the $\mathrm{CuBr} / \mathrm{O}_{2}$ catalytic system provided $3 \mathrm{a}$ in about $80 \%$ yield exclusively for both the above deuterium labeled reactions (eqn (4) and (5)). The addition of butylated hydroxytoluene (BHT) in the CuBr-catalyzed aerobic reaction strictly exacerbated the defluorination process (eqn (6)), which suggests that this reaction might involve radical intermediates. In order to

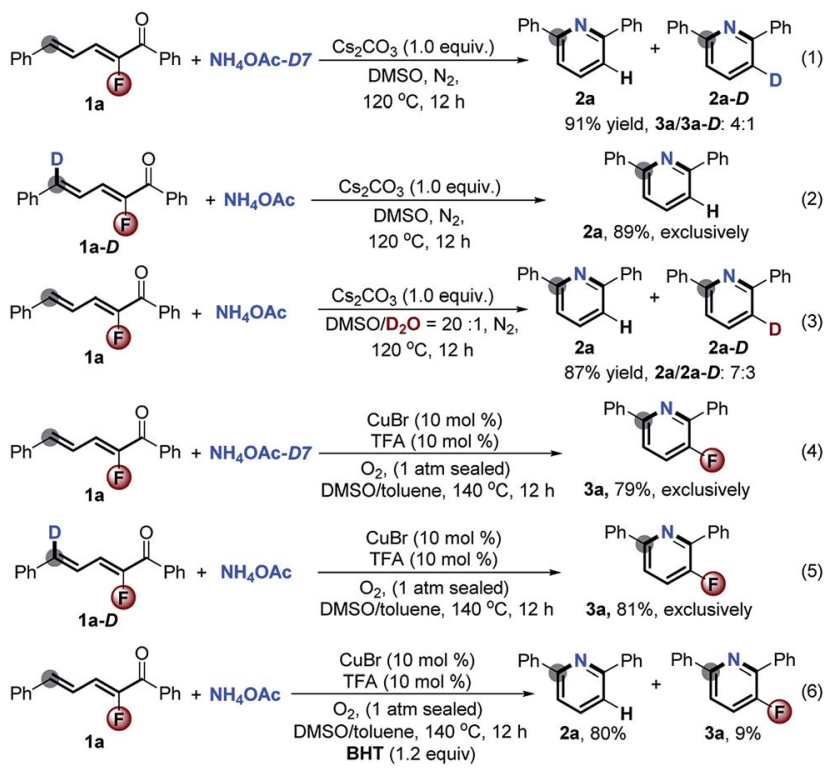

Scheme 6 Controlled reactions for mechanism investigation. verify the radical-mediated pathway, we next detected the presence of radicals by means of electron paramagnetic resonance (EPR) with the addition of 5,5-dimethyl-1-pyrroline $\mathrm{N}$ oxide (DMPO) for the reaction $2 \mathrm{a}$ and $\mathrm{NH}_{4} \mathrm{OAc}$ under $\mathrm{CuBr}$ catalyzed aerobic conditions. Fortunately, the sextet signal for $\cdot \mathrm{O}_{2}$ - was captured, while no signal was observed during the $\mathrm{Cs}_{2} \mathrm{CO}_{3}$-promoted reaction (see the ESI $\dagger$ ). All of the results reasonably confirmed our initial hypothesis (Scheme 1, eqn (3)). The 3-fluoro-2H-pyridin-1-ide Meisenheimer-type anion intermediate underwent a non-redox defluorination process under basic conditions, and the $\mathrm{CuBr}$ catalytic aerobic conditions promoted it to an unfavored non-defluorination via a SET/ radical pathway. ${ }^{7}$

\section{Conclusions}

In summary, we developed a versatile strategy towards chemoselective synthesis of diverse pyridines via the straightforward [5 +1 ] aromatic cyclization of 2-fluoro-2,4-dien-1-ones with ammonium salts. By controlling the oriented conversion of Meisenheimer-type nitrogen anion and radical intermediates under basic and $\mathrm{CuBr}$-catalyzed aerobic reaction conditions, unique chemoselectivity in defluorination and nondefluorination was realized. The synthetic utility of this strategy was highlighted by the concise synthesis of several Fmodified bioactive compounds.

\section{Conflicts of interest}

There are no conflicts to declare.

\section{Acknowledgements}

Financial support from the Hundred Talent Program of Chinese Academy of Sciences (CAS), the Natural Science Foundation of Jiangsu (Grant No. BK20160396) and CAS "Light of West China" Program is gratefully acknowledged. We are grateful to Professor Xiaobing Wan (Chemical Engineering and Materials Science, Soochow University) for his help on EPR experiment.

\section{Notes and references}

1 (a) K. Müller, C. Faeh and F. Diederich, Science, 2007, 317, 1881; (b) Fluorinated Heterocyclic Compounds: Synthesis, Chemistry, and Application, ed. V. A. Petrov, John Wiley and Sons, Inc, Hoboken, 2009; (c) T. Ahrens, J. Kohlmann, M. Ahrens and T. Braun, Chem. Rev., 2015, 115, 931; (d) V. G. Nenajdenko, V. M. Muzalevskiy and A. V. Shastin, Chem. Rev., 2015, 115, 973; (e) E. P. Gillis, K. J. Eastman, M. D. Hill, D. J. Donnelly and N. A. Meanwell, J. Med. Chem., 2015, 58, 8315; (f) C. Ni and J. Hu, Chem. Soc. Rev., 2016, 45, 5441.

2 (a) S. Purser, P. R. Moore, S. Swallow and V. Gouverneur, Chem. Soc. Rev., 2008, 37, 320; (b) E. P. Gillis, K. J. Eastman, M. D. Hill, D. J. Donnelly and N. A. Meanwell, J. Med. Chem., 2015, 58, 8315; (c) H.-J. Böhm, D. Banner, S. Bendels, M. Kansy, B. Kuhn, K. Müller, U. Obst-Sander 
and M. Stahl, ChemBioChem, 2004, 5, 637; (d) K. Müller, C. Faeh and F. Diederich, Science, 2007, 317, 1881.

3 (a) J. March, Advanced Organic Chemistry: Reactions, Mechanisms, and Structure, Wiley, New York, 1992, pp. 641676; (b) M. Bella, S. Kobbelgaard and K. A. Jørgensen, J. Am. Chem. Soc., 2005, 127, 3670; (c) I.-H. Um, S.-W. Min and J. M. Dust, J. Org. Chem., 2007, 72, 8797; (d) I.-H. Um, L.-R. Im, J.-S. Kang, S. S. Bursey and J. M. Dust, J. Org. Chem., 2012, 77, 9738; (e) S. Shirakawa, K. Koga, T. Tokuda, K. Yamamoto and K. Maruoka, Angew. Chem., Int. Ed., 2014, 53, 6220; (f) D. Sadowsky, K. McNeill and C. J. Cramer, Environ. Sci. Technol., 2014, 48, 10904; (g) S. Senaweera and J. D. Weaver, Chem. Commun., 2017, 53, 7545; (h) A. J. J. Lennox, Angew. Chem., Int. Ed., 2018, 57, 14686.

4 (a) Y.-J. Wu, in Progress in Heterocyclic Chemistry, ed. G. W. Gribble and J. A. Joule, Elsevier, Amsterdam, 2012; (b) V. A. F. F. M. Santos, L. O. Regasini, C. R. Nogueira, G. D. Passerini, I. Martinez, V. S. Bolzani, M. A. S. Graminha, R. M. B. Cicarelli and M. Furlan, J. Nat. Prod., 2012, 75, 991; (c) M. Baumann and I. R. Baxendale, Beilstein J. Org. Chem., 2013, 9, 2265; (d) C. Allais, J.-M. Grassot, J. Rodriguez and T. Constantieux, Chem. Rev., 2014, 114, 10829-10868; (e) T. L. S. Kishbaugh, Curr. Top. Med. Chem., 2016, 16, 3274; (f) L.-G. Xie, S. Shaaban, X. Chen and N. Maulide, Angew. Chem., Int. Ed., 2016, 55,
12864; (g) Z. Zhao, H. Wei, K. Xiao, B. Cheng, H. Zhai and Y. Li, Angew. Chem., Int. Ed., 2019, 58, 1148.

5 (a) A. M. Shestopalov, A. A. Shestopalov, L. A. Rodinovskaya and A. V. Gromova, in Fluorinated Heterocyclic Compounds: Synthesis, Chemistry, and Applications, Part I, ed. V. A. Petrov, Wiley, Hoboken, 2009, vol. 1, pp 243-272; (b) S. Chen, R. G. Bergman and J. A. Ellman, Org. Lett., 2015, 17, 2567; (c) S. I. Scherbinina, O. V. Fedorov, V. V. Levin, V. A. Kokorekin, M. I. Struchkova and A. D. Dilman, J. Org. Chem., 2017, 82, 12967; (d) M. Soethoudt, S. C. Stolze, M. V. Westphal, L. van Stralen, A. Martella, E. J. van Rooden, W. Guba, Z. V. Varga, H. Deng, S. I. van Kasteren, U. Grether, A. P. IJzerman, P. Pacher, E. M. Carreira, H. S. Overkleeft, A. Ioan-Facsinay, L. H. Heitman and M. van der Stelt, J. Am. Chem. Soc., 2018, 140, 6067.

6 (a) X. Wu, K. Li, S. Wang, C. Liu and A. Lei, Org. Lett., 2016, 18, 56-59; (b) Z. Song, X. Huang, W. Yi and W. Zhang, Org. Lett., 2016, 18, 5640-5643.

7 (a) X. Lia and N. Jiao, Chin. J. Chem., 2017, 35, 1349; (b) C. E. Elwell, N. L. Gagnon, B. D. Neisen, D. Dhar, A. D. Spaeth, G. M. Yee and W. B. Tolman, Chem. Rev., 2017, 117, 2059.

8 P. Harikishore, M. Pankaj, P. Vrajesh and K. V. V. M. Sairam, WO Patent 2013132509, 2013.

9 L. Chen, L. Feng, M. Huang, J. Li, F. Nan, T. Pang, L. Yu and M. Zhang, WO Patent 2011033099, 2011. 